\title{
Medical Image of the Week: Tracheal Stenosis
}

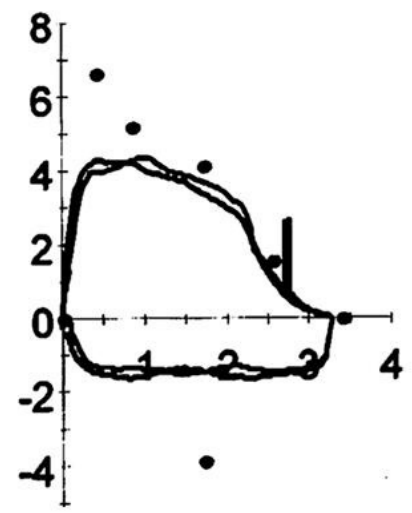

Figure 1. Pulmonary function tests showing a flat inspiratory loop.

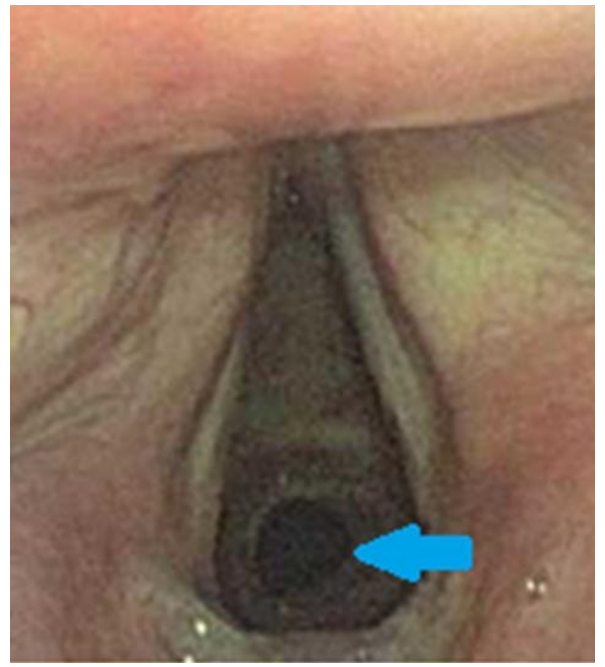

Figure 2. When viewed from vocal cords, tracheal stenosis seen distally (arrow).

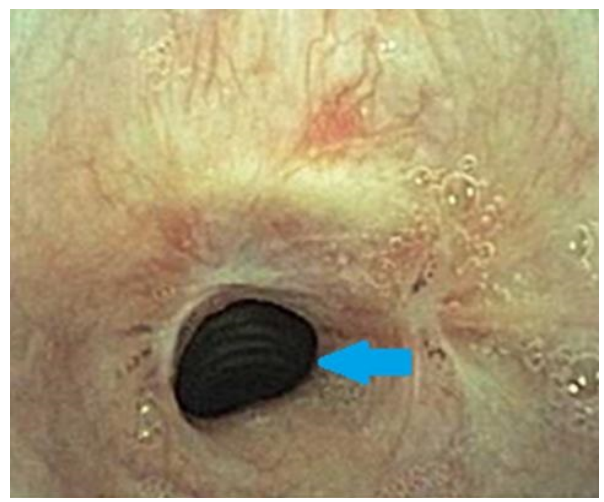

Figure 3. Tracheal stenosis seen on bronchoscopy (arrow). 


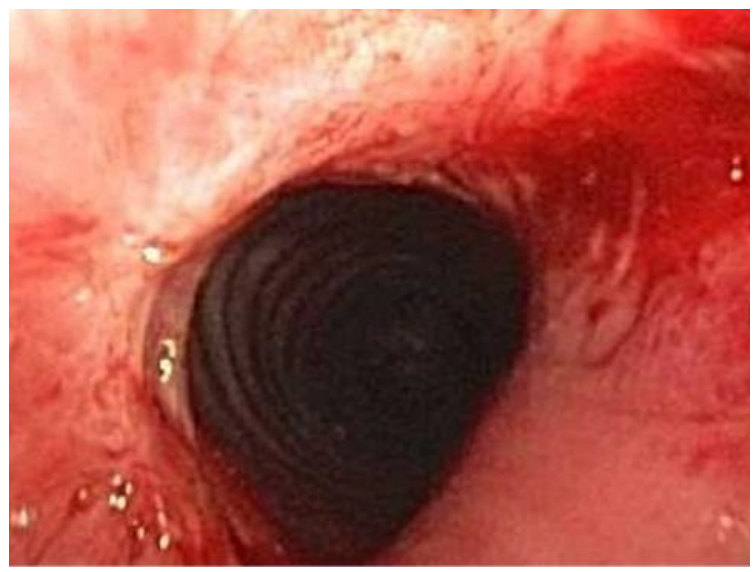

Figure 4. Area of tracheal stenosis after balloon dilation.

A 43-year-old woman was seen in clinic for dyspnea on exertion that began several months ago. Prior workup included a computed tomography of the chest with mild narrowing noted in the upper trachea. Pulmonary function tests (Figure 1) showed a flat inspiratory loop with a normal expiratory loop, which suggests a variable extrathoracic obstruction. On bronchoscopy, a tracheal stenosis was seen just past the vocal cords (Figure 2, Figure 3). Balloon dilation (Figure 4) of the stenosis returned the area to normal caliber.

Wendy Hsu, MD and James Knepler, MD Division of Pulmonary and Critical Care University of Arizona

Tucson, AZ 